\title{
Effectiveness of a Pulse Oximetric Screening for the Detection of Congenital Heart Disease in Asymptomatic New-Borns- An Observational Study.
}

\author{
Shaik Nazeer Ahmed \\ ${ }^{1}$ Associate professor, Dept of Pediatrics, Narayana medical college, Nellore, Andhra Pradesh.
}

\section{Abstract}

Background: This study was designed to evaluate the effectiveness of routine postnatal clinical examination and pulse oximetry screening in detecting congenital heart disease in new-borns. Subjects and Methods: The term new-born babies born in narayana medical college and Hospital during the study period of 12 months had a thorough clinical examination on day 2 of life with emphasis on peripheral pulses, cyanosis, tachypnea, cardiac pulsations and murmurs. Pulse oximetry screening was done within 4hrs of birth and at 48-72hrs of life. Chest Xray, ECG and Echocardiogram were done for those babies with either abnormal clinical examination or pulse oximetry reading. Clinical examination was done again 2 weeks after discharge. Results: The sensitivity $26 \%$ for oximetry alone and $60 \%$ for clinical examination alone. Specificity was $99.8 \%$ for pulse oximetry alone, and $98 \%$ for clinical examination alone. Conclusion: Pulse oximetry can enhance the clinician's ability to detect life threatening CHD in a timely manner.

Keywords: Congenital heart disease, Clinical examination, Pulse oximetry, Asymptomatic new-borns.

Corresponding Author: Dr. Shaik Nazeer Ahmed, Associate professor, Dept of Pediatrics, Narayana medical college, Nellore, Andhra Pradesh.

Received: January 2019

Accepted: February 2019

\section{Introduction}

Every year 6-8/1,000 babies are born with congenital heart disease, of these babies $25 \%$ will have critical congenital heart disease ${ }^{[1]}$ Clinical examination alone fails to detect more than $50 \%$ of babies with congenital heart disease (CHD). ${ }^{2]}$ While infants with CHD can have a normal physical examination in immediate new born period with no heart murmur and no clinical cyanosis and most will have hypoxemia in new-born period and allowed it to be used as a screening test for congenital heart disease. Early diagnosis of CHD is important because delay in diagnosis can lead to sudden detioration and even death. ${ }^{[1]}$

Incidence of congenital heart disease is estimated at 0.4 to $0.8 \%$ in studies from various parts of the world. Congenital heart disease occurs in approximately 1 per cent of live born children, but in a much higher percentage of those aborted spontaneously or stillborn. ${ }^{[3,4]}$ To detect as many as possible with CHD, including those with mild lesions, very intensive studies are needed. Studies that are not so intensive, especially those done before modern diagnostic techniques were in general use, considerably underestimated the incidence of CHD in live born children. It appears that the incidence of CHD and of the various individual lesions does not differ in different countries or at different times, providing the ascertainment of CHD is complete and accurate. ${ }^{[5,6]}$
The commonest form of CHD is the ventricular septal defect. Many children with CHD are not detected in the nursery, and undiagnosed CHD is an important source of morbidity and mortality. Prevalence of CHD in India varies from as low as 2.25 to 5.2 per 1000 live births. ${ }^{[7,8]}$ Many authors conducted a prospective study to determine the incidence of congenital heart disease among hospital live births in India.43 of 10,964 infants had congenital heart disease with an incidence of 3.9/1000 live births. ${ }^{[7-9]}$

In asymptomatic infants Pulse oximetry has been used as a screening method for CHD in new-born period. It is a noninvasive, cost effective, accurate and specific screening tool for an early detection of critical congenital cardiovascular malformations. ${ }^{[3]}$ Echocardiography is the gold standard for detecting CHD, however it is impractical to use echocardiography as a screening tool in new-borns. ${ }^{[7]}$

Those babies who survived a missed diagnosis of critical congenital heart disease have more complications and morbidity than patients who were diagnosed in a timely manner. ${ }^{[8]}$ Hence there is a need to improve the screening methods to increase the detection of CHD in neonates. This study is an attempt to increase the effectiveness of screening of CHD by combining clinical examination and pulse oximetry in new-borns.

Approximately one quarter of these children will have critical congenital heart disease, which by definition requires surgery or catheter intervention in the first year of life. Because timely recognition of CCHD could improve 
outcomes, it is important to identify and evaluate strategies to enhance early detection. Pulse oximetry has been shown to be a useful tool in the detection of previously unrecognized critical congenital heart disease. ${ }^{[5,9,10]}$

\section{Subjects and Methods}

1000 new-born babies born in Narayana medical college and hospital during a period of 12 months were observed. Pulse oximetry was done within first 4 hours of life and after $48 \mathrm{hrs}$ (48-72hrs). It was performed on either right or left foot of the baby while the baby was quiet after feeding. As soon as the PO measurement showed a good pulse wave, the maximal value was noted. $\mathrm{SpO} 2$ of $95 \%$ or more was considered as normal.

In the case of an asymptomatic infant with borderline values $(90-94 \%)$ a second measurement was performed within $1 \mathrm{hr}$. If the saturation remained below $95 \%$, echocardiography was performed. If the saturation is $<90 \%$, echocardiography was performed immediately by the cardiologist.

A follow up for all babies was done after 2 weeks in their first post neonatal visit. In this follow up clinical examination was done to rule out CHD.

\section{Inclusion criteria}

1000 new-born babies delivered in Narayana Medical College Hospital.

\section{Exclusion criteria}

1. New-born with respiratory disorder.

2. Premature babies less than 37 weeks of gestation.

3. Extremely low birth weight babies

\section{Results}

Table 1: SpO2< 4 hrs vs CHD.

\begin{tabular}{|c|c|c|c|c|c|c|}
\hline & \multicolumn{3}{|c|}{ Acyanotic/ cyanotic } & \multirow[t]{2}{*}{ Total } \\
\hline & & & Acyanotic & cyanotic & PPHN & \\
\hline \multirow[t]{2}{*}{1.00} & Count & 11 & 0 & 0 & 12 & \\
\hline & $\% \mathrm{w}$ & $66.7 \%$ & $.0 \%$ & $.0 \%$ & $50.0 \%$ & \\
\hline \multirow[t]{2}{*}{2.00} & Count & 6 & 5 & 1 & 12 & \\
\hline & $\% \mathrm{w}$ & $33.3 \%$ & $100.0 \%$ & $100.0 \%$ & $50.0 \%$ & \\
\hline \multicolumn{2}{|c|}{ Total } & Count & 18 & 5 & 1 & 24 \\
\hline & & $\% \mathrm{w}$ & $100.0 \%$ & $100.0 \%$ & $100.0 \%$ & $100.0 \%$ \\
\hline
\end{tabular}

A total of 1000 new-born babies were screened. New-borns with respiratory distress syndrome, premature babies(less than 37weeks), and extremely low birth babies were excluded. In all babies, $\mathrm{SpO} 2$ reading is initially measured within 4 hrs of delivery. All babies underwent clinical examination on day 2. Those who had murmur and those with $\mathrm{SpO} 2$ values were below $95 \%$ were evaluated with chest X-ray, ECG and ECHO. SpO2 measurements were repeated $48 \mathrm{hrs}$ after birth.

Antenatal scan detected 2 cases of congenital heart disease. One was severe pulmonary stenosis. Other one was DORV with pulmonary atresia.
Gestational complications were seen in 5 babies. One mother had fever with rash. Baby had bounding peripheral pulses, murmur, SpO2 within normal limits. On echo, PDA was diagnosed. In 4 babies mothers had gestational diabetes. 2 were taking insulin treatment. One baby had large VSD with left ventricular hypertrophy, whose mother was not on treatment.

One baby who had SpO2<95\% was detected to have PPHN, without any CHD. Out of the 18 acyanotic CHDs, only 6 showed abnormal spo2 within 4 hrs while all the cases (5) with Cyanotic CHD showed abnormal spo 2 within $4 \mathrm{hrs}$. The one with abnormal spo 2 and no significant CHD turned out to be PPHN. Six acyanotic heart disease with low SpO2 was associated with severe PPHN (large VSD with PPHN). $\mathrm{P}$ value is 0.000 (highly significant) [Table 1].

Table 2: SpO2 within 4 Hrs Vs CHD

\begin{tabular}{|l|l|l|}
\hline SpO2<4hrs & Number & Percent \\
\hline Normal & 12 & 52.18 \\
\hline Abnormal & 11 & 47.82 \\
\hline Total & 23 & 100.0 \\
\hline
\end{tabular}

Among the 11 abnormal values 5 were CHD, 6 were acyanotic heart disease with PPHN [Table 2].

Table 3: Sensitivity and specificity of $\mathrm{SpO} 2$ (within $4 \mathrm{hrs}$ ) for CHD

\begin{tabular}{|c|c|c|}
\hline \multirow[t]{2}{*}{ SpO2<4 hrs } & \multicolumn{2}{|c|}{ CHD } \\
\hline & Present & Absent \\
\hline Abnormal & 11 & 1 \\
\hline Normal & 12 & 976 \\
\hline \multicolumn{2}{|c|}{ Sensitivity $=47.8 \%$} & $=99.8 \%$ \\
\hline \multicolumn{3}{|c|}{ Positive predictive value $=91.66 \%$} \\
\hline \multicolumn{3}{|c|}{ Table 4: SpO2 Within 4 hrs Vs CHD. } \\
\hline $\mathrm{SpO2}<4 \mathrm{hr}$ & Number & Percent \\
\hline Normal & 0 & 0.00 \\
\hline Abnormal & 5 & 100.0 \\
\hline Total & 5 & 100.0 \\
\hline
\end{tabular}

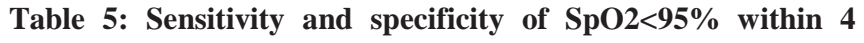
hours vs. cyanotic heart disease

\begin{tabular}{|l|l|l|}
\hline \multirow{2}{*}{$\begin{array}{l}\text { SpO2 value } \\
\text { within 4hrs }\end{array}$} & \multicolumn{2}{|c|}{ CCHD } \\
\cline { 2 - 3 } SPO2 $<95 \%$ & Present & Absent \\
\hline SPO2 $>95 \%$ & 0 & 7 \\
\hline Sensitivity $=100 \%$ & Positive predictive value $=41.6 \%$ \\
\hline Specificity $=99.2 \%$ \\
\hline
\end{tabular}

Table 6: SpO2 within 48-72 hrs.vs. CHD.

\begin{tabular}{|l|l|l|}
\hline $\begin{array}{l}\text { SpO2 within 48 - } \\
\text { 72hrs }\end{array}$ & Number & Percent \\
\hline$>95 \%$ & 993 & 99.3 \\
\hline$<95 \%$ & 7 & .7 \\
\hline Total & 1000 & 100.0 \\
\hline
\end{tabular}

Five babies had CCHD, one ACHD with severe PPHN, one with severe PPHN [Table 6].

Table 7: SpO2 between 48-72 hrs. vs CHD.

\begin{tabular}{|l|l|l}
\hline SpO2 within 48-72 hrs.' & Number & Percent \\
\hline Normal & 17 & 73.91 \\
\hline
\end{tabular}




\begin{tabular}{|l|l|l|}
\hline Abnormal & 6 & 26.09 \\
\hline Total & 23 & 100.0 \\
\hline
\end{tabular}

After 48 hrs 7 babies had SpO2 less than 95\%, 5 had cyanotic heart disease, 1 had acyanotic heart disease with severe PPHN. One had only severe PPHN [Table 7].

Table 8: Sensitivity and specificity ofSpO2 within 48-72hrs for
CHD.
\begin{tabular}{|l|l|l|}
\hline SpO2 within 48- 72hrs & CHD Present & Absent \\
\hline Spo2 $>48$ hrs.' $<95 \%$ & 6 & 1 \\
\hline$>95 \%$ & 17 & 976 \\
\hline Sensitivity $=35.2 \%$ & Positive predictive value $=85.71 \%$ \\
\hline Specificity=99.8\% & \multicolumn{2}{|l|}{} \\
\hline
\end{tabular}

Table 9: SpO2 within 48-72 hrs vs. CCHD

\begin{tabular}{|l|l|l|l|l|l|}
\hline \multicolumn{2}{|l|}{ SpO2 } & Cyanotic & Cyanotic & Total \\
\hline $\begin{array}{l}\text { Spo2 } \\
\text { within } \\
\text { n 48- }\end{array}$ & $>95 \%$ & Count & 17 & 0 & 17 \\
\cline { 4 - 6 } & & $94.4 \%$ & $.0 \%$ & $70.8 \%$ \\
\hline \multirow{2}{*}{ 72 Hrs. } & $>95 \%$ & Count & 1 & 5 & 6 \\
\cline { 4 - 6 } & & $5.6 \%$ & $100.0 \%$ & $29.2 \%$ \\
\hline Total & \multirow{2}{*}{ Count } & 18 & 5 & 23 \\
\cline { 4 - 5 } & & $100.0 \%$ & $100.0 \%$ & $100.0 \%$ \\
\hline
\end{tabular}

$\mathrm{P}$ value 0.000 (highly significant)

Table 10: Sensitivity and specificity of SpO2 within 48-72hrs for cyanotic congenital heart disease

\begin{tabular}{|l|l|l|}
\hline \multirow{2}{*}{$\begin{array}{l}\text { 7202 within } 48 \\
\text { 72hrs }\end{array}$} & \multicolumn{2}{|l|}{ CCHD } \\
\cline { 2 - 3 } Spo2<95\% & 5 & Absent \\
\hline Spo2 $>95 \%$ & 0 & 2 \\
\hline Sensitivity y $=100 \%$ & 993 \\
\hline Positive Predictive Value $=71.42 \%$ \\
\hline
\end{tabular}

Table 11: Chest $x$-ray vs. congenital heart diseases

\begin{tabular}{|l|l|l|}
\hline CXR & Number & Percent \\
\hline Not done & 975 & 97.5 \\
\hline Normal & 19 & 1.9 \\
\hline Abnormal & 6 & .6 \\
\hline Total & 1000 & 100.0 \\
\hline
\end{tabular}

Chest $\mathrm{x}$-ray was abnormal in 4 cyanotic congenital heart disease and 2 acyanotic heart disease.

Table 12: ECHO Vs. congenital heart diseases

\begin{tabular}{|l|l|l|}
\hline ECHO & Number & Percent \\
\hline Not done & 975 & 97.5 \\
\hline Normal & 2 & .2 \\
\hline Abnormal & 23 & 2.1 \\
\hline Total & 1000 & 100.0 \\
\hline
\end{tabular}

One baby with murmur had no CHD in echo. One with severe PPHN.

\section{Discussion}

According to literature congenital heart disease is a gross structural malformation of the heart disease or great intrathoracic vessels with a real or potential functional importance. ${ }^{[11,12]}$ Early recognition of Congenital Heart
Disease (CHD) is of crucial importance because clinical presentation and deterioration may be sudden. Many children with undetected complex CHD die at presentation or before their first surgical intervention. Clinical examination for the early signs of CHD is an essential part of routine neonatal examination and can identify some asymptomatic new-borns. Pulse oximetry has been suggested as a screening tool for the early detection of CHD in asymptomatic new-borns, because the physical examination alone appears to be in-sufficient. In our study two $(8 \%)$ cyanotic CHD were antenatally detected by scan. Twenty congenital heart diseases were missed by antenatal scan. Thus prenatal diagnosis should not be overestimated and could lead todangerous overconfidence. In a study, only $28 \%$ of CHD were detected prenatally technology assessment reports, shows the rate for antenatal scan is low. ${ }^{[13]}$

Two babies with acyanotic heart disease were found to have gestational complications for mother. One had gestational diabetes mellitus, echocardiography for the new-born showed large VSD and LVH. Other one had fever and rashes during pregnancy, clinical examination for the baby showed bounding peripheral pulses and systolic murmur. Echo showed PDA.

All non cyanotic CHD except one were detected by murmur. We couldn't detect murmur within $48 \mathrm{hrs}$ of birth, but on follow up murmur was present. In our study, clinical examination showed a sensitivity of $60 \%$, specificity of 98\%, and PPV of $95.23 \%$.For CCHD, sensitivity was $60 \%$, specificity was $98 \%$ and of PPV of $14.62 \%$. A study showed ${ }^{[14]}$ about $54 \%$ of babies with murmur on routine clinical examination had structural heart disease. Another study also proved the importance of clinical examination. In their study, ${ }^{[15]} 73 \%$ of infants with CHD (29/40) had a murmur at the time echocardiography was performed. Out of them, only $35 \%$ of cyanotic CHD (6/17) presented with a murmur, whereas all non-cyanotic CHD (23/23) were detected by means of a murmur. These results confirm the importance of clinical examination, but also that the presence of a murmur does not correlate well with the severity of the cardiac lesion. Certain studies also proved that the presence of murmur does not correlate with severity of the lesion. ${ }^{[15,16]}$

Clinical examination for the early signs of CHD is an essential part of routine clinical examination. Respiratory rate and abnormal pulses showed no significant relationship with CHD. One baby with bounding peripheral pulse was detected to have PDA in echocardiography. Cyanosis presented in 3 cyanotic heart diseases. This study suggests that the presence of abnormal clinical signs like murmur should warrant a prompt cardiac evaluation. In our study, $82 \%$ of babies with murmur had structural heart disease. In our study we detected murmur in twenty babies. Two babies had cyanotic CHD. One baby with murmur showed no CHD in Echo. Murmur was not present in three cyanotic heart 
diseases. One baby had no murmur in clinical examination but $\mathrm{SpO} 2$ was below 95 in two readings. Echo done showed PPHN and ASD. On follow up after 2 weeks, murmur was detected.

A recent study showed a sensitivity y of $46 \%$ for clinical examination. ${ }^{[1]}$ Specificity was $100 \%$.Vaidyanathan and colleagues study had 157 patients $(2.9 \%)$ with positive clinical examination, the most common being murmur (84 patients, 1.6\%).Clinical evaluation was positive in only 3 patients (17.6\%) with major and 32 patients (7.8\%) with minor CHD. The sensitivity y for clinical examination in their study was $9.26 \%$.Pulse oximetry has been suggested as a screening tool for the early detection of CHD in asymptomatic new-born.

We took the saturation cut off as $95 \%$ as this reflects published normal Pox values in healthy new-borns. We measured only leg saturation as both upper-limb and lower limb measurements are time consuming. A study measured oxygen saturation in upper and lower limbs of 22 babies with known cyanotic congenital heart disease and found out that the difference in saturation between upper and lower limbs in babies with obligatory right to left ductal shunts was at least $7 \%$, implying a post ductal saturation of at most $93 \%$ in these cases. ${ }^{[17]}$

The optimal measurement time remains uncertain. We did pulse oximetry screening within $4 \mathrm{hrs}$ of birth and between 48-72 hrs.' of birth. In our study after $48 \mathrm{hrs}$ of birth the average age at screening was about $52 \mathrm{hrs}$. Echocardiography studies have shown that complete closure of the ductus arteriosus occurs in less than $10 \%$ of full-term new-borns before $12 \mathrm{hrs}$ of age, in $50 \%$ of new-borns by about $24 \mathrm{hrs}$, and in $81 \%$ of new-borns by $48 \mathrm{hrs}$.Performing pulse oximetry screening at less than 6hrs of age when some new-borns may still have persistent ductal shunting, could result in false positives. If Pox screening is performed after a few days of life, there will be reduced incidence of false positives, because of the physiologic decrease in the pulmonary vascular resistance, but a new-born with a ductal dependent CHD could deteriorate rapidly if the DA has already closed.

Measurement performed shortly after birth may lead to increased number of echocardiograms. ${ }^{[18]}$ But this would allow the anticipation of clinically critical situations, which can result in higher morbidity and neurological squeal. False positive Pox readings due to pulmonary hypertension can be of benefit because they lead to careful clinical examination and echocardiography, and ,therefore ,to correct management of the patient with no delay. In order to shorten the hospital stay, there is a tendency to do $\mathrm{SpO} 2$ screening on the first day of life that can lead to false positives and unnecessary interventions in some cases. In our study pulse oximetry screening within 4 hrs had sensitivity of $47.8 \%$, specificity of $99.8 \%$, and positive predictive value of 91.66\%.Screening after 48 hours showed a sensitivity of $26 \%$, specificity of $99.8 \%$, and PPV of $85.71 \%$.
Limitations of the study

This study has some limitations. (1) The sample size is small. (2) Echocardiogram couldn't be done for all thousand babies. (3) Follow up for clinical examination was done after two weeks for many of the babies but couldn't be done for all the babies. So we could have missed a small number of infants diagnosed elsewhere.

\section{Conclusion}

Pulse-oximetry screening offers an effective and reliable means for detecting cyanotic CHD in asymptomatic newborns.

\section{References}

1. Arlettaz R, Seraina A, Monkhoff M et al. The contribution of pulse oximetry to the early detection of congenital heart disease in newborns. Eur J Pediatr. 2006; 165: 94-98.

2. Rosati E, Chitano G, Dipaola L et al. Indications and limitations for a neonatal pulse oximetry screening of critical congenital heart disease. J Perinat Med.2005;33(5):455-7

3. Knowles R, Griebsch I, Dezateux C, et al. Newborn screening for congenital heart defects: a systematic review and cost -effectiveness analysis. Health Technol Assess. 2005 Nov;9(44):1-152, iii-iv

4. R Krishna Kumar, Diagnosis and Initial Management of Heart Disease in the New-born, R Krishna Kumar, Shakunthala S Prabhu,M Zujfikar Ahamed.IAP speciality series on paediatric cardiology, First edn, Vol 1,Jaypee Pub 2008, Chapter 25,225-228.

5. M.William, N. Jane, M. Paul et al. Role of pulse oximetry in examining New-borns for congenital heart disease. Journal of the American heart association.2009;120:000-000

6. Hoffman JI. Kaplan S. The incidence of congenital heart disease. J Am Collcardiol 2002; 39:1890-19006.

7. Anitha Saxena Congenital heart disease in India. Indian J Pediatr 2005;72( 7)595-598

8. Abdulla $\mathrm{R}$. What is the prevalence of congenital heart diseas? Ped Cardiol 1997;18:268..Khalil A, Agarwal R, Thirupuram S, Arora R. Incidence of congenital Heart disease among hospital live births in India. Indian Pediatrics.1994; 31:519-27.

9. Samenk M, Salvik Z. Differences in the incidence of congenital heart defects in boys and girls. Cesk pediatric.1990; 45 (4):214-216.

10. Rothan AJ, Flyer DC.Sex, Birth order, and maternal age characteristics of infants with congenital heart defects. Am J Epidemol. 1976;104(5):527-34

11. Jordan SC, Olive S. Heart Disease in Pediatrics. Third Edition; W. B Saunders Company,Philadelphia;1989:3-7

12. Oram S.Congenital heart disease. Second edition; William Heinemann Medical books Ltd,London;1981:461-71

13. Hassan J,Haleem AA,Bhutta ZA.J Pak Med Assoc.1997;47(3):78-81

14. Benson PF,Bonham-Carter RE, Smellie JM. Transient and Intermittent murmurs in new-born infants Lancet 1961;i:627-630

15. Allan LD.A practical approach to fetal heart scanning. Semin Perinatol.2000;24:324-330

16. Acharya G, Sitras V, Maltau JM, Dahl LB, Kaaresen PI, Hanssen TA, Lunde P. Major congenital heart disease in Northern Norway: shortcomings of pre- and postnatal diagnosis. Acta Obstet Gyneco 1 Scand.2004;83:1124- 1129

17. Hunter S, Heads A, Wyllie J, Robson S. Prenatal diagnosis of congenital heart disease in the northern region of England: benefitsof a training programme for obstetric ultrasonographers. Heart.2000;84 :294-298.

18. Klein SK, Cans C, Robert E, Jouk PS. Efficacy of routine fetal ultrasound screening for congenital heart disease in Isère County, France. Prenat Diagn. 1999;19:318-322. 
Copyright: () the author(s), 2019. It is an open-access article distributed under the terms of the Creative Commons Attribution License (CC BY 4.0), which permits authors to retain ownership of the copyright for their content, and allow anyone to download, reuse, reprint, modify, distribute and/or copy the content as long as the original authors and source are cited.

How to cite this article: Ahmed SN. Effectiveness of a Pulse Oximetric Screening for the Detection of Congenital Heart Disease in Asymptomatic New-Borns- An Observational Study. Asian J. Clin. Pediatr. Neonatol.2019;7(1):46-50.

DOI: dx.doi.org/10.21276/ajcpn.2019.7.1.11

Source of Support: Nil, Conflict of Interest: None declared. 